a highly infectious source case. Should all strongly positive tuberculin reactors in the schools' BCG vaccination programme receive chemoprophylaxis as Dr Festenstein suggests? We believe that chemoprophylaxis should be offered only to high risk groups that is, those with a recent contact history or residents in a high prevalence area within the previous two years. The reason for this is that the predictive value of a positive tuberculin test (for true tuberculous infection) is low in populations with a low incidence of infection (such as schoolchildren) as compared with, say, contacts of tuberculosis or entrants from high risk countries. Thus, if the Heaf test has $95 \%$ sensitivity and $98 \%$ specificity, the predictive value of a positive test is only $32 \%$ in a population having $1 \%$ incidence of tuberculous infection. In such a population, therefore, two out of every three subjects receiving chemoprophylaxis (for a positive tuberculin test) will not, in fact, have tuberculous infection. For similar reasons the routine screening of domestic contacts of tuberculin positive schoolchildren is unproductive.

I strongly agree with Dr Festenstein that physicians specialising in sexually transmitted diseases should liaise closely with colleagues in charge of tuberculosis contact tracing in the event of dual diagnosis (HIV and tuberculosis) in the index case to ensure that all cases of tuberculosis are notified and that the possibility of HIV positivity in contacts can be borne in mind.

CRAIG SKINNER Foint Tuberculosis Committee,
The British Thoracic Society, 1 St Andrew's Place, London NW1 4LB,

$U K$

1 Brindle RJ, Nunn PP, Githui W, Allen BW, Gathua S, Waiyaki P. Quantitative bacillary
response to treatment in HIV-associated pulresponse to treatment in HIV-associated pul147:958-61.

2 Festenstein F, Empey DW, Rudd RM. Tuberculosis in Britain. BMF 1990;300:1339.

3 Skinner C. Tuberculosis in Britain. BMF 1990; 300:1724.

4 Departments of Health, Joint Committee on Vaccination and Immunisation. Immunisation against infectious disease. London: HMSO, 1992.

\section{Non-invasive mechanical ventilation in acute respiratory failure}

Ambrosino and colleagues (July 1995;50: 755-7) report their experience of using noninvasive positive pressure ventilation in 59 episodes of acute respiratory failure in 47 patients with chronic obstructive pulmonary disease (COPD). In this study, non-invasive ventilation was unsuccessful in those patients who were most acidotic at presentation. However, the degree of acidosis developed during an exacerbation is a major feature in determining survival in patients with COPD. ${ }^{1}$ It is these patients, often with frequent admissions and for whom invasive ventilation on the intensive care unit is inappropriate, who are most in need of ventilatory assistance. In addition, the overall mortality rate of $8.5 \%$ in this study, despite the use of non-invasive ventilation in all cases, is comparable with some other studies using conventional treatment alone. ${ }^{12}$

Non-invasive ventilation has attracted much enthusiastic support, but there still appears to be insufficient evidence of the benefits offered by this technique to support its widespread use. A randomised controlled trial in comparison with conventional therapy (including doxapram) is still needed.

\section{F M HARDINGE Osler Chest Unit, Churchill Hospital,} Oxford OX3 $7 L \mathcal{F}$, UK

1 Jeffrey AA, Warren PM, Flenley DC. Acute hypercapnic respiratory failure in patients with chronic obstructive lung disease: risk factors and use of guidelines for management. Thorax 1992;47:34-40.

2 Martin TR, Lewis SW, Albert RK. The prognosis of patients with chronic obstructive pulmonary disease after hospitalisation for acute respiratory failure. Chest 1982;82:310-4.

\section{BOOK NOTICE}

Interfacing the IBM-PC to Medical Equipment. RWD Nickalls and R Ramasubramanian. (Pp 402; $£ 37.50$ (US\$ 59.95)). Cambridge: Cambridge University Press, 1995. 0521462800

This book "represents an attempt to bring together both details of serial communications as they relate to an IBM-compatible $\mathrm{PC}$, and the problems associated with interfacing specific items of equipment". To achieve this, the authors have divided this 400 page book into three sections: I - The serial interface, II - Miscellaneous topics, and III - The equipment. There are nine appendices.

Part I provides an outline to the RS-232 standard, how to transmit data, controlling the flow of data, the communication ports on the PC, and how to program in QuickBasic. Whilst this section explains in reasonable detail the important concepts of linking the medical equipment to PC computers, it is rather heavy going and the more general reader will probably skip most of the technical jargon and simply pick out the important bits of information. However, you will be able to communicate in interface-speak.

Part II provides a very brief overview of running Kermit - a communication software program. There are better texts and overviews of this elsewhere. The electrical safety section is also brief, but does permit the non-electronics expert to comprehend the "dos" and "don'ts" of interfacing electrical equipment to the patient. The data analysis section is short and provides some useful, but rather limited information. This could be much more comprehensive and consequently more helpful.

Part III should be the most useful. Interfacing four makes of pulse oximeter (Ohmeda 3700/3740, Nellcor, Novametrix and Minolta Pulsox-7), Datex anaesthetic monitors, two syringe pumps, two ventilators (Ohmeda 7800 and Drager Evita) and the Vitalograph Compact II spirometer are all covered. Each section covers communication modes, the ports available, the cable connections, programs for data collection in realtime or from memory output. Some of this information is provided in the user/maintenance manuals and some of the software is commercially available. Only one system has an example of the type of output. It would have been more useful to have included examples of data analysis and possible outputs available, which is what the end user actually wants. Each chapter is comprehensive and, with some knowledge, the programs could be installed and tested by a user with some experience of programming and debugging. I do have some reservations as to why some equipment needs to be interfaced to a computer.

Overall, this book provides an "attempt" at bringing together much information that is available in numerous other texts, some of which are easier for the less knowledgeable reader. Clearly by trying to bring all of this information together the authors have been constrained by space and cost at providing a more comprehensive overview of the problems, the programs, and their outputs. A paperback edition would have been cheaper and would perhaps have permitted more information to be given for the same price. It is to be hoped that the second edition is an improvement. Doubtless this book will find a place in some medical physics/bioengineering reference libraries. - AHK.

NOTICE

\section{Scadding-Morriston Davies Joint Fellowship in Respiratory Medicine 1996}

This fellowship is available to support visits to medical centres in the UK or abroad for the purpose of undertaking studies related to respiratory medicine. Medical graduates practising in the UK, including consultants and irrespective of the number of years in that grade, may apply. Applicants should submit a curriculum vitae together with a detailed account of the duration and nature of the work, the centres to be visited, confirming that these have agreed to provide the facilities required, and giving the sum of money needed for travel and subsistence (there is no application form). A sum of up to $£ 12000$ can be awarded to the successful applicant, or the sum may be divided to support two or more applications. Applications should be sent by 31 January 1996 to Dr I A Campbell, Secretary to the Scadding-Morriston Davies Fellowship, Llandough Hospital, Penarth, South Glamorgan CF64 2XX.

\section{CORRECTION}

\section{Review of prescription of domiciliary long term oxygen therapy in Scotland}

In the paper entitled "Review of prescription of domiciliary long term oxygen therapy in Scotland" by D Morrison et al which appeared on pages $1103-5$ of the October issue, line 10 of the second column on page 1104 should read "However, $\mathbf{5 1 \%}$ of these measurements were performed when the patients were clinically unstable ..." 